This document is confidential and is proprietary to the American Chemical Society and its authors. Do not copy or disclose without written permission. If you have received this item in error, notify the sender and delete all copies.

\title{
Membrane-Anchoring, Comb-Like Pseudopeptides for Efficient, pH-Mediated Membrane Destabilization and Intracellular Delivery
}

\begin{tabular}{|r|l|}
\hline Journal: & ACS Applied Materials \& Interfaces \\
\hline Manuscript ID & am-2017-00498d.R1 \\
\hline Manuscript Type: & Article \\
\hline Date Submitted by the Author: & 09-Feb-2017 \\
\hline Complete List of Authors: & $\begin{array}{l}\text { Chen, Siyuan; Imperial College London, Chemical Engineering } \\
\text { Wang, Shiqi; Imperial College London, Department of Chemical } \\
\text { Engineering } \\
\text { Kopytynski,, Michal; Imperial College London, Department of Chemical } \\
\text { Engineering } \\
\text { Bachelet, Marie; Imperial College London, Department of Chemical } \\
\text { Engineering } \\
\text { Chen, Rongjun; Imperial College London, Department of Chemical } \\
\text { Engineering }\end{array}$ \\
\hline
\end{tabular}




\section{Membrane-Anchoring, Comb-Like Pseudopeptides for Efficient, $\mathrm{pH}-$ Mediated Membrane Destabilization and Intracellular Delivery}

Siyuan Chen, Shiqi Wang, Michal Kopytynski, Marie Bachelet, Rongjun Chen ${ }^{*}$

Department of Chemical Engineering, Imperial College London, South Kensington Campus, London, SW7 2AZ, United Kingdom

KEYWORDS: pH-responsive; pseudopeptide; endonsomal escape; drug delivery; comb-like polymer 


\begin{abstract}
Endosomal release has been identified as a rate-limiting step for intracellular delivery of therapeutic agents, in particular macromolecular drugs. Herein, we report a series of synthetic pH-responsive, membrane-anchoring polymers exhibiting dramatic endosomolytic activity for efficient intracellular delivery. The comb-like pseudopeptidic polymers were synthesized by grafting different amounts of decylamine (NDA), which act as hydrophobic membrane anchors, onto the pendant carboxylic acid groups of a pseudopeptide, poly (L-lysine isophthalamide). The effects of the hydrophobic relatively long alkyl side chains on aqueous solution properties, cell membrane destabilization activity and in-vitro cytotoxicity were investigated. The optimal polymer containing $18 \mathrm{~mol} \%$ NDA exhibited limited hemolysis at $\mathrm{pH} 7.4$, but induced nearly complete membrane destabilization at endosomal $\mathrm{pH}$ within only $20 \mathrm{~min}$. The mechanistic investigation of membrane destabilization suggests the polymermediated pore formation. It has been demonstrated that the polymer with hydrophobic side chains displayed a considerable endosomolytic ability to release endocytosed materials into the cytoplasm of various cell lines, which is of critical importance for intracellular drug delivery applications.
\end{abstract}




\section{INTRODUCTION}

Efficient cytoplasmic delivery of therapeutic agents, in particular macromolecular drugs, remains a key limitation to their therapeutic effect. ${ }^{1}$ Without egress, the endocytosed contents are generally routed for lysosomal degradation. ${ }^{2}$ Influenza viruses can utilize hemagglutinin HA-2 N-terminal fusogenic peptides to disrupt the endosomal membrane at acidic $\mathrm{pH}$ and allow efficient escape of the viral nucleic acid from the endosome into the cytoplasm before the lysosomal fusion process occurs. ${ }^{3,4}$ However, the clinical application of viral vectors for drug delivery is usually limited due to safety issues and difficulties in large-scale production. It is therefore increasingly important to develop endosomolytic non-viral vectors, which can release the internalized active compounds into the cytoplasm without lysosomal degradation. ${ }^{5-8}$

Particular interest has been focused on development of anionic polymers as drug carriers to mimic the $\mathrm{pH}$-dependent membrane disruptive behavior of fusogenic viral peptides. ${ }^{9-11}$ The polyanions containing both hydrophobic segments and weakly ionizable carboxyl groups can exhibit more favorable biodistribution and significantly lower cytotoxicity compared to polycations. $^{12}$ As $\mathrm{pH}$ decreases below their $\mathrm{pKa}$, they display a coil-to-globule conformational change due to the protonation of carboxylate ions, which, as a result, leads to lipid membrane destabilization. ${ }^{13}$ Manipulating the hydrophobic/hydrophilic balance of the anionic polymers is crucial to enhance their membrane destabilization activity. ${ }^{14-16}$ Efforts on improving hydrophobicity of the anionic endosomolytic polymers have been so far mainly focused on incorporation with short hydrophobic pendant groups, such as vinyl poly $(\alpha-$ alkylacrylic acid) polymers bearing pendant $\mathrm{C} 1-\mathrm{C} 5$ alkyl groups ${ }^{17,18}$ and pseudopeptidic polymers bearing pendant hydrophobic natural amino acids ${ }^{19}$.

In nature, however, many membrane proteins contain covalently attached long-chain fatty acids, which can act as hydrophobic anchors inserting into the lipid bilayer to facilitate the 
membrane binding. These membrane proteins may have more than one attached long-chain moiety to ensure sufficiently strong hydrophobic interaction with the membrane. ${ }^{20}$ Inspired by the membrane-anchoring proteins, long aliphatic chains can be incorporated onto a polymer backbone to form a "comb-like" polymer architecture, which is distinct from the linear or branched polymer, to enhance the polymer-membrane interaction.

Eccleston et al. have developed a biodegradable, metabolite-derived, anionic pseudopeptide, poly(L-lysine iso-phthalamide) (PLP) consisting of a hydrophobic backbone and pendant carboxyl groups. ${ }^{21}$ The amphiphilic pseudopeptide does not contain long aliphatic chains that are present in many membrane proteins, and displays low cell membrane disruptive capacity only at relatively low $\mathrm{pH}(4.5-5.0)$, which is outside the endosomal $\mathrm{pH}$ range. ${ }^{22}$ Herein, we report a series of comb-like polymers synthesized by grafting hydrophobic decylamine (NDA) onto the carboxylic acid groups along the PLP backbone at different densities. The effects of the conjugated relatively long chains on the $\mathrm{pH}-$ responsiveness of polymer conformation and membrane destabilization were investigated. The mechanism of cell membrane disruption mediated by the comb-like polymers was elucidated. Their cytotoxicity and ability to release endocytosed materials from endosomes into the cytoplasm of different types of cancerous and non-cancerous mammalian cells were also evaluated.

\section{MATERIALS AND METHODS}

\subsection{Materials}

Decylamine, pyrene, calcein, fluorescein isothiocyanate-dextran (FITC-dextran, average $\mathrm{M}_{\mathrm{w}}$ of $4 \mathrm{k}, 10 \mathrm{k}, 70 \mathrm{k}, 150 \mathrm{k}$ and $2000 \mathrm{k}$ Da respectively), iso-phthaloyl chloride, Dulbecco's modified Eagle's medium (DMEM), fetal bovine serum (FBS), Eagle's minimum essential medium (MEM) non-essential amino acid solution, penicillin and Dulbecco's phosphate buffered saline (D-PBS) were purchased from Sigma Aldrich (Dorset, UK). Dimethyl 
sulfoxide (DMSO), triethylamine, $N, N$-dimethylformamide (DMF), 4-dimethylaminopyridine (DMAP), sodium chloride, alamarBlue ${ }^{\circledR}$, Texas $\operatorname{Red}^{\circledR}$ hydrazide, LysoTracker ${ }^{\circledR}$ Red DND-99 and Hoechst 33342 were obtained from Fisher Scientific (Loughborough, UK). L-lysine methyl ester dihydrochloride, $N, N^{\prime}$-dicyclohexylcarbodiimide (DCC) and ninhydrin were purchased from Alfa Aesar (Heysham, UK). Anhydrous ethanol, acetone, hydrochloric acid, potassium carbonate, sodium hydroxide, chloroform, methanol, diethyl ether, sodium citrate dehydrate, trithylamine and sodium phosphate were obtained from VWR (Lutterworth, UK). Defibrinated sheep red blood cells (RBCs) were purchased from TCS Biosciences Ltd (Buckingham, UK).

\subsection{Synthesis of PLP and Comb-Like Polymers}

Poly(L-lysine iso-phthalamide) (PLP) was synthesized according to the previously published method. ${ }^{21}$ NDA was conjugated onto the pendant carboxylic acid moieties along the PLP backbone (designated as PLP-NDA) at various degrees of substitution via DCC/DMAP mediated amide coupling chemistry (Scheme 1). Briefly, PLP (3 g) and DMAP (0.6 g, $20 \mathrm{wt} \%$ of PLP) were dissolved in $60 \mathrm{~mL}$ anhydrous DMSO/DMF (1:3 v/v). A specific amount of NDA was dissolved in $2 \mathrm{~mL}$ of chloroform and then transferred to the reaction solution, to which was added dropwise DCC (3 molar equivalents of NDA) in $10 \mathrm{~mL}$ anhydrous DMF. The reaction was monitored by thin-layer chromatography $\left(\mathrm{CHCl}_{3}: \mathrm{MeOH}\right.$ :trithylamine $=8: 2: 0.2$, using ninhydrin to visualize amine $)$. Solid impurities were removed by vacuum filtration and the reaction solution was added with $20 \mathrm{~mL} 5 \mathrm{wt} \%$ $\mathrm{NaOH}$ in anhydrous ethanol and then precipitated rapidly into five volumes of diethyl ether. The precipitate was collected and re-dissolved in deionized water. $0.2 \mathrm{M} \mathrm{HCl}$ solution was then used to precipitate the polymer out. The precipitate was collected by vacuum filtration and re-dissolved in deionized water with $0.2 \mathrm{M} \mathrm{NaOH}$. The precipitation-filtration- 
redissolution process was repeated twice to remove inorganic salts and residual organic solvents. The polymer was further purified by dialysis against deionized water in a Visking dialysis tubing (Medicell, UK, MWCO 12-14 kDa) to remove oligomers. After dialysis, the polymer solution was titrated to $\mathrm{pH} 7.4$ using $0.2 \mathrm{M} \mathrm{NaOH}$ and then lyophilized to a fine white powder. To prepare its acidic form, the dialyzed polymer solution was acidified to around $\mathrm{pH} 3.0$ using $0.2 \mathrm{M} \mathrm{HCl}$. The precipitate was collected by vacuum filtration and lyophilized.

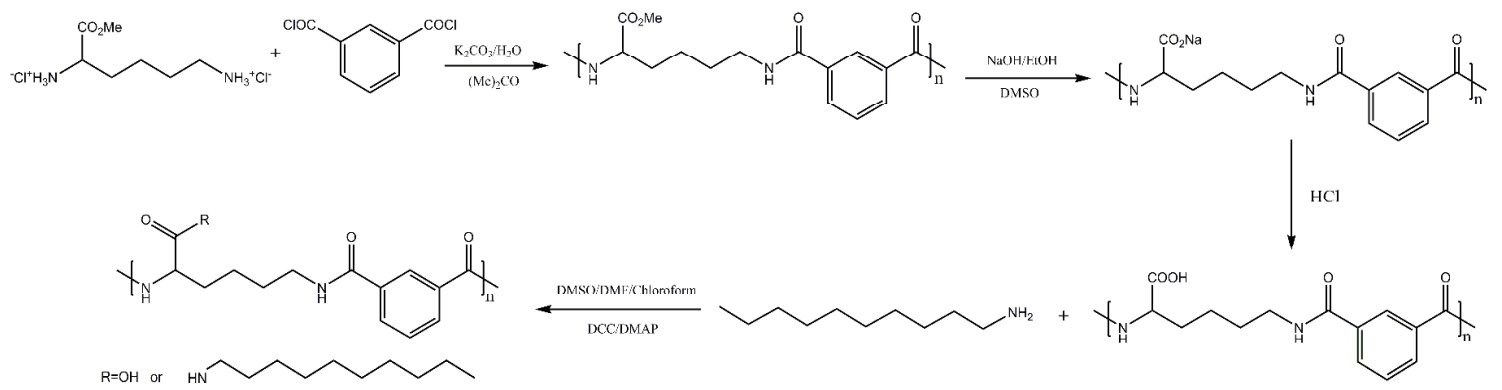

Scheme 1. Synthesis of poly(L-lysine iso-phthalamide)s grafted with NDA (PLP-NDA).

\subsection{Structural Characterization}

The polymers in acidic form were dissolved in $\mathrm{d}^{6}$-DMSO and their ${ }^{1} \mathrm{H}-\mathrm{NMR}$ spectra were obtained on a $400 \mathrm{MHz}$ NMR spectrometer (Bruker, Germany) at room temperature (Figure $\mathrm{S} 1)$. The ratio of the integral $0.77-0.91 \mathrm{ppm}$ to the integral $7.45-7.64 \mathrm{ppm}$ was used to calculate the degree of grafting $\mathrm{n} \%$, which denotes to the actual molar percentage of NDA relative to the pendant carboxylic acid groups along the backbone of PLP. The molecular weight and polydispersity index (PDI) of PLP $\left(\mathrm{M}_{\mathrm{w}}=35.7 \mathrm{kDa}, \mathrm{M}_{\mathrm{n}}=17.9 \mathrm{kDa}, \mathrm{PDI}=1.99\right)$ were determined according to the previous publication. ${ }^{19}$ The degrees of grafting obtained from ${ }^{1} \mathrm{H}-\mathrm{NMR}$ were used to calculate the molecular weights of the comb-like pseudopeptidic polymers, e.g. PLP-NDA 3\% $\left(\mathrm{M}_{\mathrm{w}}=36.3 \mathrm{kDa}\right.$, PDI $\left.=1.99\right)$, PLP-NDA $10 \%\left(\mathrm{M}_{\mathrm{w}}=37.7 \mathrm{kDa}\right.$, 
PDI $=1.99)$ and PLP-NDA $18 \%\left(\mathrm{M}_{\mathrm{w}}=39.3 \mathrm{kDa}\right.$, PDI $\left.=1.99\right)$. The FT-IR spectra of PLPNDA in acid form were recorded on a Spectrum 100 FT-IR Spectrometer (Perkin Elmer, USA) (Figure S2), with characteristic peaks located at $3292 \mathrm{~cm}^{-1}(\mathrm{~N}-\mathrm{H}$ str and O-H str), $1724 \mathrm{~cm}^{-1}$ (C=O acid str), $1629 \mathrm{~cm}^{-1}$ (amide band I), and $1529 \mathrm{~cm}^{-1}$ (amide band II).

\subsection{Turbidimetry}

Polymer solutions were prepared in phosphate or citrate buffer $(100 \mathrm{mM})$ at specific $\mathrm{pHs}$ and allowed to equilibrate for $48 \mathrm{~h}$. The transmittance of the polymer solutions at different pHs was measured using a Genesys 10S UV-vis spectrophotometer (Thermo Scientific, UK) at $480 \mathrm{~nm}$.

\subsection{Fluorescence Spectroscopy}

The hydrophobic pyrene has been previously employed as a probe to investigate the $\mathrm{pH}$ induced hydrophobic association of polymers in aqueous solution. ${ }^{19,23} 1.0 \mathrm{mM}$ pyrene stock solution was freshly prepared in absolute methanol and then added to each polymer solution at a specific $\mathrm{pH}$ to give a final pyrene concentration of $600 \mathrm{nM}$. The polymer solutions were equilibrated for $48 \mathrm{~h}$ with protection from light. The excitation spectra $\left(\lambda_{\mathrm{em}}=390 \mathrm{~nm}\right)$ of pyrene dissolved in the polymer solutions were recorded on a FluoroMax spectrofluorometer (HORIBA, Japan). The ratio of the fluorescence intensities at $338 \mathrm{~nm}$ to $333 \mathrm{~nm}$ in the excitation spectra of pyrene, $I_{338} / I_{333}$, was then calculated. The critical aggregation concentrations (CACs) of the polymers were obtained from the concentration-dependent variations of $I_{338} / I_{333}$ at $\mathrm{pH} 7.4$.

\subsection{Dynamic Light Scattering (DLS)}


The hydrodynamic size and size distribution of the polymers in aqueous solution were investigated using a dynamic light scattering platform (Zetasizer Nano S, Malvern, UK). The polymer aqueous solutions were prepared in the buffer at specific $\mathrm{pHs}$ and equilibrated for 48 h. All the samples were filtered through $0.45 \mu \mathrm{m}$ filters before measurements. The dynamic light scattering was then measured at a scattering angle of $137^{\circ}$ in a $10-\mathrm{mm}$ diameter cell at $25^{\circ} \mathrm{C}$, repeated for eleven times for each run.

\subsection{Hemolysis Assay}

The membrane disruptive activity of the polymers was examined using a previously established hemolysis model. ${ }^{24}$ Briefly, the polymer solutions at different concentrations were prepared in the $100 \mathrm{mM}$ phosphate buffer or citric buffer at specific pHs. Defibrinated sheep RBCs were washed at least three times with $150 \mathrm{mM} \mathrm{NaCl}$ solution and resuspended in the polymer buffer solution to a final concentration of $1-2 \times 10^{8} \mathrm{RBCs} \mathrm{mL}^{-1}$. Negative and positive controls were prepared by resuspending RBCs in buffer alone and deionized water respectively. The samples were incubated in a shaking water bath $(120 \mathrm{rpm})$ at $37^{\circ} \mathrm{C}$ for $1 \mathrm{~h}$, and then centrifuged at $4000 \mathrm{rpm}$ for $4 \mathrm{~min}$. The absorbance of the supernatant at $540 \mathrm{~nm}$ was measured using the UV-vis spectrophotometer and relative hemolysis was calculated.

\subsection{Laser Scanning Confocal Microscopy of non-nucleated RBCs}

Laser scanning confocal microscopy of RBCs was performed to elucidate the mechanism of the polymer-induced cell membrane destabilization. RBCs were washed with $150 \mathrm{mM}$ $\mathrm{NaCl}$ solution for three times, and then resuspended in the buffer solutions at specific $\mathrm{pHs}$ containing $10 \mu \mathrm{M}$ FITC-dextran and $1 \mu \mathrm{M}$ Texas $\operatorname{Red}^{\circledR}$ hydrazide (with or without the polymers) to a final cell concentration of $10^{7} \mathrm{RBCs}^{-1}$. The cells were imaged using an 
LSM-510 inverted laser scanning confocal microscope (Zeiss, Germany) at $37^{\circ} \mathrm{C}$. FITC and Texas $\operatorname{Red}^{\circledR}$ hydrazide were excited at 488 and $543 \mathrm{~nm}$ respectively.

\subsection{Cell Culture}

Two adherent epithelial cancer cell lines, HeLa derived from human cervical carcinoma and A549 derived from human lung carcinoma, were grown in DMEM supplemented with $10 \%(\mathrm{v} / \mathrm{v}) \mathrm{FBS}$ and $100 \mathrm{U} \mathrm{mL}^{-1}$ penicillin unless specified otherwise. The non-cancerous $\mathrm{CHO}$ adherent cell line derived from the ovary of the Chinese hamster were grown in DMEM supplemented with 1\% MEM non-essential amino acids, 10\% (v/v) FBS and $100 \mathrm{U} \mathrm{mL}^{-1}$ penicillin unless specified otherwise. The cells were trypsinized using trypsin-EDTA and maintained in a humidified incubator with $5 \% \mathrm{CO}_{2}$ at $37^{\circ} \mathrm{C}$.

\subsection{Alamar Blue Assay}

The cytotoxicity of the polymers was evaluated by Alamar Blue assay. HeLa, CHO or A549 cells were seeded into a 96-well plate (Corning, USA) containing the complete DMEM $\left(0.1 \mathrm{~mL}\right.$ per well) at a density of $1 \times 10^{4}$ cells per well for $24 \mathrm{~h}$. The spent medium was replaced with $0.1 \mathrm{~mL}$ of the $0.22 \mu \mathrm{m}$ filter-sterilized serum-free DMEM containing the polymer at specific concentrations. After certain periods of incubation, the polymercontaining medium was replaced with the complete DMEM containing $10 \%(\mathrm{v} / \mathrm{v})$ alamarBlue $^{\circledR}$. The plate was further incubated for $4 \mathrm{~h}$ according to the manufacturer's instructions and the fluorescence of each well was measured using a spectrofluorometer $\left(\right.$ GloMax $^{\circledR}$-Multi Detection System, Promega, USA) at the excitation wavelength of $525 \mathrm{~nm}$ and the emission wavelength of 580-640 nm. The cytotoxic effect was determined from the fluorescence readings. 


\subsection{Laser Scanning Confocal Microscopy of Nucleated Mammalian Cells}

Calcein, known as a membrane-impermeable fluorophore, was employed to evaluate the ability of the comb-like polymers to release endocytosed molecules into the cytoplasm of different cells. $2 \mathrm{~mL}$ of HeLa, CHO or A549 cells $\left(2 \times 10^{5}\right.$ cells $\left.\mathrm{mL}^{-1}\right)$ were seeded into a 35mm glass-bottom culture dish (MatTek, USA) and cultured for $24 \mathrm{~h}$. The spent medium was then replaced by $2 \mathrm{~mL}$ of the $0.22 \mu \mathrm{m}$ filter-sterilized serum-free medium containing the polymer $\left(0.5 \mathrm{mg} \mathrm{mL}^{-1}\right)$ and calcein $\left(2 \mathrm{mg} \mathrm{mL}^{-1}\right)$. The cells were incubated with $2 \mathrm{mg} \mathrm{mL}^{-1}$ calcein alone as a control. After treatment with or without polymer for a specific period, the cells were washed three times with D-PBS and replenished with the complete DMEM for further incubation. LysoTracker $(50 \mathrm{nM})$ and Hoechst $33342\left(1 \mu \mathrm{g} \mathrm{mL} \mathrm{L}^{-1}\right)$ were employed to stain endosomal/lysosome and nuclei respectively for $5 \mathrm{~min}$ and then the cells were washed with D-PBS three times. The cells were imaged using the LSM-510 inverted laser scanning confocal microscope. Calcein was excited using a $488 \mathrm{~nm}$ laser and the emission at $535 \mathrm{~nm}$ was collected.

\subsection{Statistical Analysis}

All data points were repeated in triplicates $(n=3)$. Reported results and graphical data are mean values with standard deviation encompassing a $95 \%$ confidence interval.

\section{RESULTS AND DISCUSSION}

\subsection{Aqueous Solution Properties}

The $\mathrm{pH}$-mediated phase separation of the comb-like PLP-NDA polymers bearing different amounts of the hydrophobic relatively long side chains was determined at polymer concentration of $1.0 \mathrm{mg} \mathrm{mL}^{-1}$. The $\mathrm{pH}$ value at the onset of precipitation $\left(\mathrm{pH}_{\mathrm{p}}\right)$, at which the transmittance started to decrease, can be manipulated by varying the degree of substitution 
with NDA. As shown in Figure S3, compared with the linear counterpart PLP, the comb-like polymers with a degree of substitution $\leq 10 \mathrm{~mol} \%$, e.g. PLP-NDA $3 \%$ and PLP-NDA $10 \%$, displayed a negligible change in $\mathrm{pH}_{\mathrm{p}}$. With further increasing the molar percentage of NDA moieties, the $\mathrm{pH}_{\mathrm{p}}$ value increased from 4.5 for PLP to 5.0 for PLP-NDA $18 \%$. This suggests that incorporation with hydrophobic NDA side chains can result in enhanced polymer hydrophobicity. This is consistent with the report that the increased amount of hydrophobic amino acid pendant groups increased the hydrophobicity of polymer. ${ }^{19,23}$

The poorly water-soluble pyrene was used as a probe to investigate the $\mathrm{pH}$-mediated hydrophobic association of the polymers. The ratio of fluorescence intensities at 338 to 333 $\mathrm{nm}$ in the excitation spectra of pyrene $\left(I_{338} / I_{333}\right)$ increases upon its transfer into a less polar environment. ${ }^{23}$ Herein, the changes in $I_{338} / I_{333}$ were used to evaluate the effects of the relatively long aliphatic side chains and the polymer concentration on the hydrophobic association of the comb-like polymers. Figure 1A shows the changes of $I_{338} / I_{333}$ as a function of $\mathrm{pH}$ in the aqueous solutions of PLP, PLP-NDA 3\%, PLP-NDA 10\% and PLP-NDA $18 \%$ at the concentration of $0.5 \mathrm{mg} \mathrm{mL} \mathrm{L}^{-1}$. The $\mathrm{pH}$ at the onset of hydrophobic association $\left(\mathrm{pH}_{\mathrm{h}}\right)$, defined as the $\mathrm{pH}$ value where $I_{338} / I_{333}$ started to increase, was 4.8 for the linear PLP polymer. At $\mathrm{pH} \geq 4.8$, its $I_{338} / I_{333}$ value was almost constant at around 0.6 , indicating that pyrene was in a hydrophilic environment. When the $\mathrm{pH}$ decreased below 4.8, a pronounced increase in $I_{338} / I_{333}$ was observed, indicative of the transfer of pyrene to an increasingly hydrophobic environment. The rapid $\mathrm{pH}$-mediated changes in $I_{338} / I_{333}$ can be ascribed to a $\mathrm{pH}$-dependent coil-to-globule transition of polymer conformation. ${ }^{25}$ At $\mathrm{pH} 7.4$, the polymer displayed an expanded structure due to the electrostatic repulsion between negatively charged carboxylate ions. Upon acidification, the carboxylate groups were protonated and hydrophobic association became predominant, leading to the formation of a compact structure with the hydrophobic core where pyrene was preferentially solubilized. ${ }^{19}$ 
The $\mathrm{pH}$-mediated hydrophobic association was enhanced by incorporating the relatively long aliphatic side chains onto the PLP backbone. As shown in Figure 1A and Table 1, with increasing the degree of substitution up to $10 \mathrm{~mol} \%$, the comb-like polymers (e.g. PLP-NDA $3 \%$ and PLP-NDA $10 \%$ ) showed a gradual increase in $I_{338} / I_{333}$, with a concomitant increase in $\mathrm{pH}_{\mathrm{h}}$ and broadening in the $\mathrm{pH}$ range for hydrophobic association. A further increase in the degree of substitution to $18 \mathrm{~mol} \%$ (e.g. PLP-NDA 18\%) led to the almost constant $I_{338} / I_{333}$ value at $\sim 1.5$, suggesting the localization of pyrene in the hydrophobic core of compact aggregates that were formed throughout the $\mathrm{pH}$ range tested. The enhanced hydrophobic association of the comb-like PLP-NDA polymers compared to their linear counterpart PLP can be ascribed to the enhanced hydrophobicity resulting from grafting with hydrophobic NDA pendant chains. It is consistent with the observation that grafted aliphatic chains can lead to enhanced aggregation of poly(aspartic acid). ${ }^{26}$
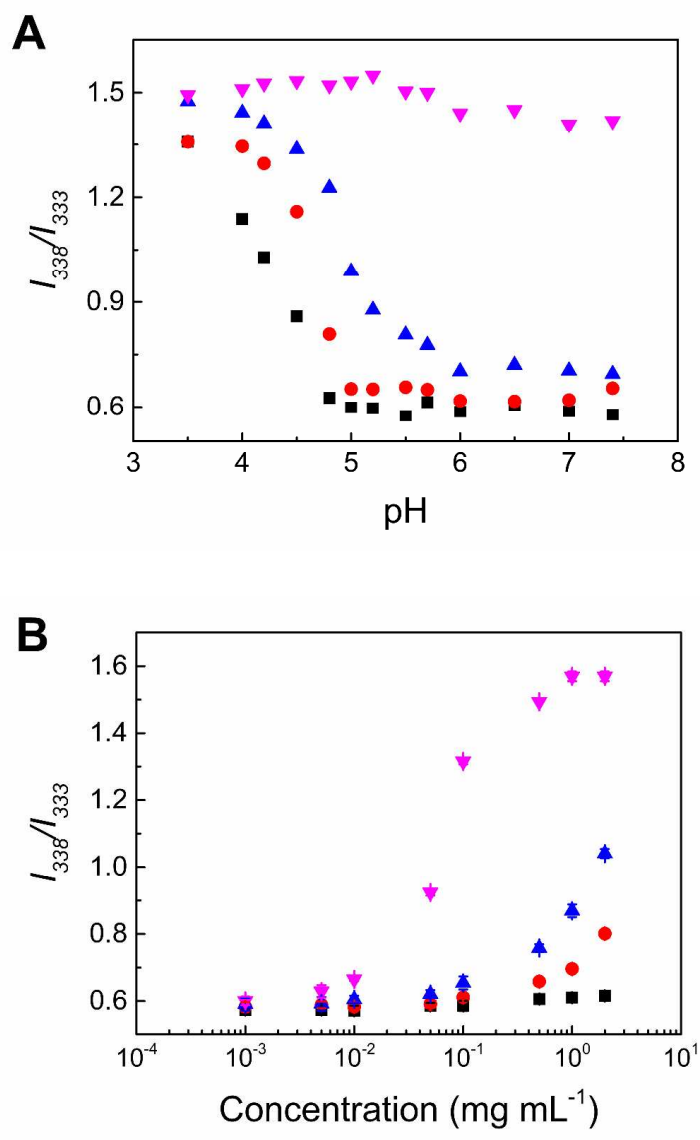
Figure 1. (A) pH-dependent variations in $I_{338} / I_{333}$ of PLP (•), PLP-NDA $3 \%(\bullet)$, PLP-NDA $10 \%(\Delta)$ and PLP-NDA $18 \%(\nabla)$ at $0.5 \mathrm{mg} \mathrm{mL}^{-1}$ in $100 \mathrm{mM}$ phosphate or citrate buffer. (B) Concentration-dependent variations in $I_{338} / I_{333}$ of PLP (•), PLP-NDA $3 \%(\bullet)$, PLP-NDA $10 \%(\Delta)$ and PLP-NDA $18 \%(\boldsymbol{\nabla})$ at pH 7.4 in $100 \mathrm{mM}$ phosphate buffer.

Table 1. The $\mathrm{pH}$ values at the onset of hydrophobic association $\left(\mathrm{pH}_{\mathrm{h}}\right)$ and $\mathrm{pH}$ ranges for hydrophobic association of PLP and the comb-like PLP-NDA polymers at $0.5 \mathrm{mg} \mathrm{mL}^{-1}$ and their critical aggregation concentrations (CACs) at $\mathrm{pH}$ 7.4.

\begin{tabular}{lllll}
\hline & PLP & PLP-NDA 3\% & PLP-NDA 10\% & PLP-NDA 18\% \\
\hline $\mathrm{pH}$ & $4.8 \pm 0.2$ & $5.0 \pm 0.2$ & $6.0 \pm 0.2$ & N/A \\
$\mathrm{pH}$ range & $3.5-4.8$ & $4.0-5.0$ & $3.5-6.0$ & N/A \\
$\mathrm{CAC}\left(\mathrm{mg} \mathrm{mL}^{-1}\right)$ & $\mathrm{N} / \mathrm{A}$ & 0.342 & 0.282 & 0.031 \\
\hline
\end{tabular}

The amphiphilic nature of the comb-like PLP-NDA polymers provides an opportunity for self-assembling into multimolecular aggregates. The variations in $I_{338} / I_{333}$ as a function of polymer concentration at $\mathrm{pH} 7.4$ were employed to determine the CAC (Figure 1B). The CAC value was obtained from the intersection of the line through the points on the rapidly varying part and the line through the points at the low-concentration extreme of the plot. Above the $\mathrm{CAC}$, the polymers tended to form multimolecular aggregates due to the predominant intermolecular interactions. As summarized in Table 1, the CAC value of the comb-like polymer decreased with increasing the molar percentage of NDA grafts, which could be attributed to the enhanced polymer hydrophobicity.

The hydrodynamic size of the pseudopeptidic polymers at $0.5 \mathrm{mg} \mathrm{mL}^{-1}$ was measured by DLS. Both the comb-like PLP-NDA polymers and their linear counterpart PLP displayed two size populations at $\mathrm{pH}$ 7.4. As shown in Figure 2, PLP had a small particle population with a 
mean size of $10.3 \pm 2.3 \mathrm{~nm}$ and a large population with a mean size of $384.2 \pm 34.5 \mathrm{~nm}$. With increasing the grafting density of NDA side chains up to $18 \mathrm{~mol} \%$, the mean size of the small population remained similar, whilst the mean size of the large population was dramatically reduced to $51.9 \pm 1.6 \mathrm{~nm}$. This was due to the enhanced intermolecular and intramolecular interactions resulting from incorporation of hydrophobic side chains. ${ }^{26,27}$

The size change of the pseudopeptides as a function of $\mathrm{pH}$ was also depicted in Figure 2. At pH 7.4 both PLP and PLP-NDA $18 \%$ formed loose aggregates, due to the predominant electrostatic repulsion between negatively charged carboxylate groups ${ }^{28}$, and thus displayed two size populations. Upon acidification to $\mathrm{pH}$ 5.5, PLP retained two size populations, but the mean particle size of its large population was reduced considerably from $384.2 \pm 34.5$ to 86.0 $\pm 10.5 \mathrm{~nm}$ (Figure 2A). This suggests that protonation of the carboxylate groups caused the enhanced hydrophobic interactions and the consequent formation of compact aggregates. As comparison, PLP-NDA $18 \%$ displayed only one small particle population with a mean hydrodynamic size of $16.4 \pm 5.6 \mathrm{~nm}$ at $\mathrm{pH} 5.5$ (Figure 2B). This was because the presence of relatively long aliphatic side chains in the comb-like polymer considerably enhanced hydrophobic interactions, which became predominant and led to the formation of a more compact structure with a single size population. It has been previously reported that the amphiphilic pseudopeptidic polymer PLP bearing poly(ethylene glycol) displayed a similar transition from a bimodal size distribution to a single-modal distribution upon acidification. ${ }^{28}$

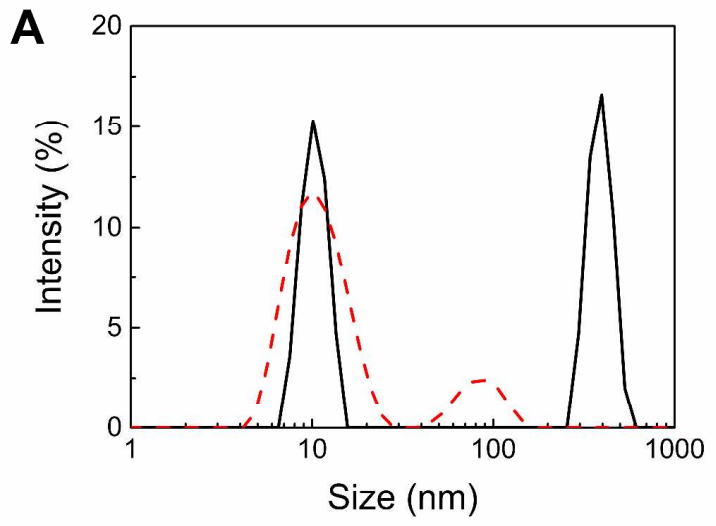

14 


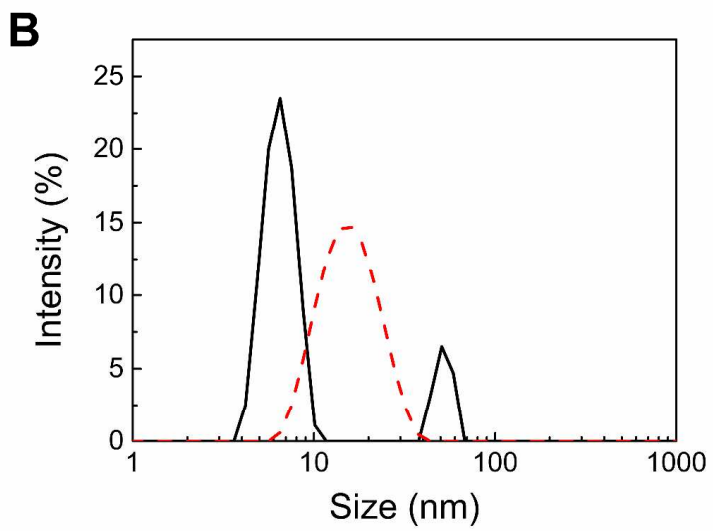

Figure 2. Particle size distribution of (A) PLP and (B) PLP-NDA $18 \%$ at $0.5 \mathrm{mg} \mathrm{mL}^{-1}$ at $\mathrm{pH}$ 7.4 (solid) and $\mathrm{pH} 5.5$ (dash).

\subsection{Cell Membrane Disruption}

The cell membrane disruptive activity of the comb-like polymers was assessed using RBC membranes as a model for endosomal membranes. ${ }^{24}$ The $\mathrm{pH}$ range of $7.4-4.5$ for the hemolysis assay mimics the gradually acidifying $\mathrm{pH}$ environment in early endosomes, late endosomes and lysosomes during the endocytic pathway. ${ }^{29}$ Figure $3 \mathrm{~A}$ shows the $\mathrm{pH}$ dependent hemolysis of PLP and the comb-like PLP-NDA polymers at $0.5 \mathrm{mg} \mathrm{mL}^{-1}$. PLP only displayed limited membrane disruption at $\mathrm{pH}$ below 5.5. In contrast, the comb-like polymers containing the hydrophobic relatively long NDA side chains exhibited negligible or limited hemolysis at physiological $\mathrm{pH}$, but exhibited significantly enhanced hemolytic activity upon acidification compared to their linear counterpart. The maximum degree of hemolysis was increased from $28.8 \pm 0.9 \%$ for PLP to $42.3 \pm 0.1 \%, 77.1 \pm 3.7 \%$ and $99.6 \pm$ $0.2 \%$ for PLP-NDA $3 \%$, PLP-NDA $10 \%$ and PLP-NDA $18 \%$ respectively. The pH for the maximum hemolysis was also increased from a lysosomal $\mathrm{pH} 4.5$ for PLP to an endosomal pH 5.5 for the three PLP-NDA polymers. It is also worth noting that increasing the degree of grafting with NDA resulted in the onset of hemolytic activity at a higher $\mathrm{pH}$ value, which as a 
consequence enabled the comb-like polymers to exhibit significantly enhanced hemolytic activity within the $\mathrm{pH}$ range $(6.0-6.8)$ typical of early endosomes ${ }^{24}$ (reaching a hemolysis of $78.3 \pm 0.2 \%$ for PLP-NDA $18 \%$ ). With acidification to $\mathrm{pH}<5.5$, the hemolysis efficiency decreased due to precipitation of the comb-like polymers. A similar effect has been reported for the hemolytic activity of the pseudopeptidic polymers bearing pendant hydrophobic natural amino acids. ${ }^{24}$

The improved cell membrane destabilizing activity of the PLP-NDA polymers could be due to their comb-like structure and enhanced hydrophobicity. The ranking of hemolytic activity at endosomal $\mathrm{pH}$ amongst the polymers was PLP $<$ PLP-NDA 3\% $<$ PLP-NDA 10\% $<$ PLP-NDA 18\%. This ranking well correlated with the NDA graft number and polymer hydrophobicity. Vial et al. have reported that amphiphilic polymers lacking hydrophobic side-chain moieties can not effectively bind or disrupt the vesicular membrane. ${ }^{30}$ It has also been shown that the hydrophobic association of poly( $\alpha$-ethylacrylic acid) containing short ethyl pendant groups can rapidly overcome the charge repulsion and therefore exhibited the improved membrane binding. ${ }^{31}$ Other researchers have reported that even a small number of long alkyl side chains can facilitate the deeper insertion of poly( $N$-isopropylacrylamides) derivatives into the liposomal bilayer. ${ }^{32}$

The ability of PLP-NDA $18 \%$ to hemolyze RBCs at endosomal pH 5.5 and physiological $\mathrm{pH}$ was further evaluated as a function of polymer concentration (Figure 3B). PLP-NDA 18\% showed limited hemolysis at $\mathrm{pH} 7.4$ within the concentration range tested $(0.005-10 \mathrm{mg}$ $\mathrm{mL}^{-1}$ ), but exhibited the dilution-independent, excellent membrane disruptive activity at $\mathrm{pH}$ 5.5 over a wide concentration range $\left(0.5-10 \mathrm{mg} \mathrm{mL} \mathrm{m}^{-1}\right)$. When diluting the polymer concentration 400 -fold to as low as $0.025 \mathrm{mg} \mathrm{mL}^{-1}$, PLP-NDA $18 \%$ still retained a high level of hemolysis of $72.9 \pm 0.5 \%$ at $\mathrm{pH} 5.5$. The dilution-independent characteristic of the comblike polymer may be attributed to its stable membrane anchoring, which resulted from the 
deep insertion of long hydrophobic side chains into the membrane. ${ }^{33}$ This dilution resistance is of critical importance for drug delivery applications since after administration, the concentration of drug delivery systems could be considerably decreased due to the dilution effect during circulation in the bloodstream. ${ }^{34}$ This profile of membrane activity at both physiological and endosomal $\mathrm{pH}$ is desirable for intracellular drug delivery applications.

The kinetics of hemolysis induced by the comb-like polymers at $0.5 \mathrm{mg} \mathrm{mL}^{-1}$ were also investigated at $\mathrm{pH}$ 5.5. As shown in Figure $3 \mathrm{C}$, after only 10 min of incubation, $72.8 \pm 1.8 \%$ of RBCs were hemolyzed by PLP-NDA $18 \%$, followed by almost complete membrane destabilization after $20 \mathrm{~min}$. As comparison, the polymers with $\leq 3 \%$ NDA showed not only lower membrane disruption but also slower kinetics. The presence of PLP-NDA 3\% resulted in the maximum degree of hemolysis of $47.1 \pm 4.0 \%$ after $50 \mathrm{~min}$, and no hemolysis was detected for the linear PLP within the time period tested at $\mathrm{pH}$ 5.5. This indicates that increasing the hydrophobicity and tuning of the comb-like architecture of the polymers could result in a stronger driving force to rapidly and effectively overcome the electrostatic repulsion from the negatively charged cell membrane, ${ }^{34}$ leading to faster membrane binding and greater membrane disruption. The fast and efficient membrane destabilization of the comb-like polymers, in particular PLP-NDA 18\%, would enable them to disrupt the endosomal membrane before the vesicular evolution from endosomes to lysosomes during the endocytic pathway, which has been reported to take several hours. ${ }^{35}$ 


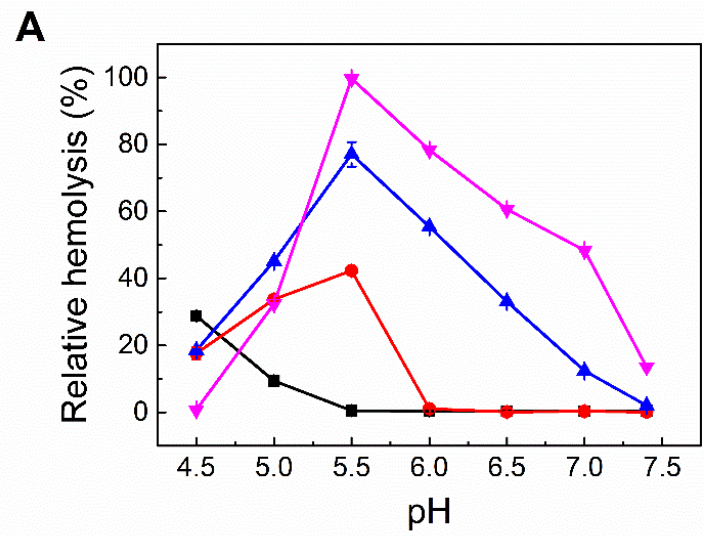

B

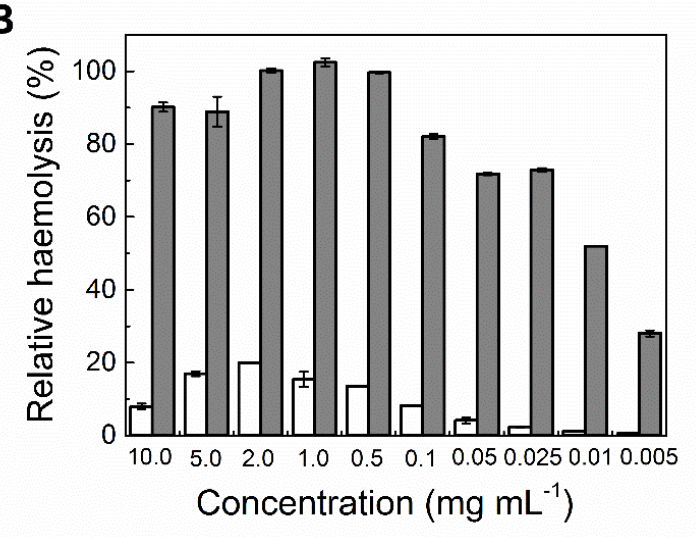

C

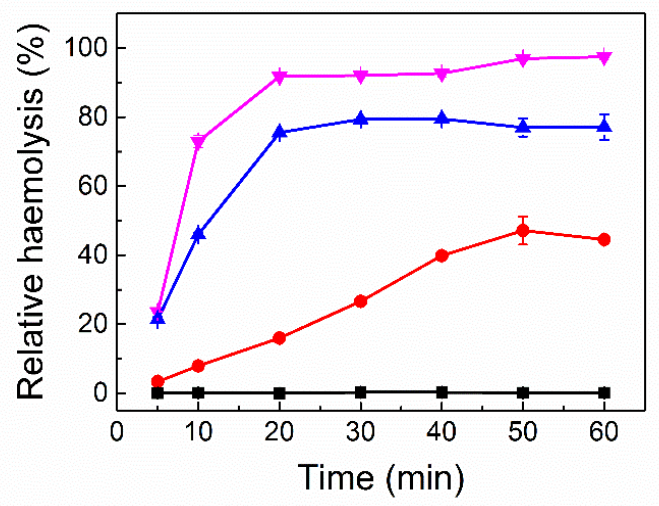

Figure 3. Relative hemolysis of RBCs in the presence of PLP and the comb-like PLP-NDA polymers. (A) pH-dependent hemolysis of RBCs incubated with PLP (•), PLP-NDA 3\% (•), PLP-NDA $10 \%(\boldsymbol{\Delta})$ and PLP-NDA $18 \%$ ( $\boldsymbol{\nabla}$ ) at $0.5 \mathrm{mg} \mathrm{mL}^{-1}$ for $1 \mathrm{~h}$. (B) Concentrationdependent hemolysis of RBCs incubated with PLP-NDA 18\% at pH 7.4 (open column) and pH 5.5 (closed column). (C) Time-dependent hemolysis of RBCs incubated with PLP (•), PLP-NDA $3 \%(\bullet)$, PLP-NDA $10 \%(\boldsymbol{\Delta})$, PLP-NDA $18 \%(\nabla)$ at $0.5 \mathrm{mg} \mathrm{mL}^{-1}$ at $\mathrm{pH} 5.5$. 


\subsection{Mechanism of Cell Membrane Disruption}

Lipid membrane disruption could be caused by membrane fusion ${ }^{36}$, pore formation ${ }^{37}$ or membrane solubilization $^{12}$. In order to investigate the mechanism of hemolysis by the comblike polymers, the RBC membrane integrity was examined by laser scanning confocal microscopy. As shown in Figures S4 and Figure 4, FITC-dextran $\left(\mathrm{M}_{\mathrm{w}}=4 \mathrm{kDa}\right)$ and Texas $\operatorname{Red}^{\circledR}$ hydrazide could not pass though the RBC membrane treated with buffer only (at both $\mathrm{pH} 7.4$ and 5.5), $0.5 \mathrm{mg} \mathrm{mL}^{-1} \mathrm{PLP}$ (at both $\mathrm{pH} 7.4$ and 5.5), or $0.5 \mathrm{mg} \mathrm{mL}^{-1}$ PLP-NDA $18 \%$ (at $\mathrm{pH}$ 7.4). However, when the RBCs were incubated with $0.5 \mathrm{mg} \mathrm{mL}^{-1}$ PLP-NDA $18 \%$ at $\mathrm{pH} 5.5$, more than $90 \%$ of the cells were turned into erythrocyte ghosts (Figure 4). The membrane of erythrocyte ghosts was brightly stained with Texas Red ${ }^{\circledR}$ hydrazide, which could react with peroxidized lipids during the formation of ghost cells to give bright red fluorescence. ${ }^{38}$ The FITC-dextran $4 \mathrm{k}$ was observed inside the erythrocyte ghosts and there was no difference in fluorescence intensity between the inside and the outside, indicating that the FITC-dextran 4k efficiently permeated through the membrane. No membrane fusion or solubilization was observed and the membrane structure was retained as shown by Texas $\operatorname{Red}^{\circledR}$ hydrazide staining, further confirming that the comb-like polymer induced pore formation and hemolysis without membrane rupture at endosomal $\mathrm{pH}$. This is different from the hemolysis mechanism of poly( $\alpha$-ethylacrylic acid) bearing pendant hydrophobic short ethyl groups, which could burst the cell membrane as a result of pore formation. ${ }^{39}$

Membrane binding and insertion are regarded as two important continuous steps for the polymer-mediated lipid membrane destabilization. ${ }^{33}$ The electrostatic repulsion between the anionic polymers and the negatively charged cell membrane could prevent the effective membrane binding and insertion of the polymers. Although the linear parent polymer PLP displayed a coil-to-globule conformational change at acidic $\mathrm{pH}^{22}$, no or low hemolysis was observed for PLP at $0.5 \mathrm{mg} \mathrm{mL}^{-1}$ within the $\mathrm{pH}$ range tested (from $\mathrm{pH} 7.4$ to 4.5 ) due to the 
limited polymer-membrane interaction. For the comb-like PLP-NDA polymers bearing hydrophobic relatively long side chains, the largely increased hydrophobic interaction could overweigh the electrostatic repulsion. Furthermore, the hydrophobic side chain could act as a membrane anchor ${ }^{40}$, leading to the pore formation in the lipid membrane upon $\mathrm{pH}$-mediated conformational change at acidic pHs.

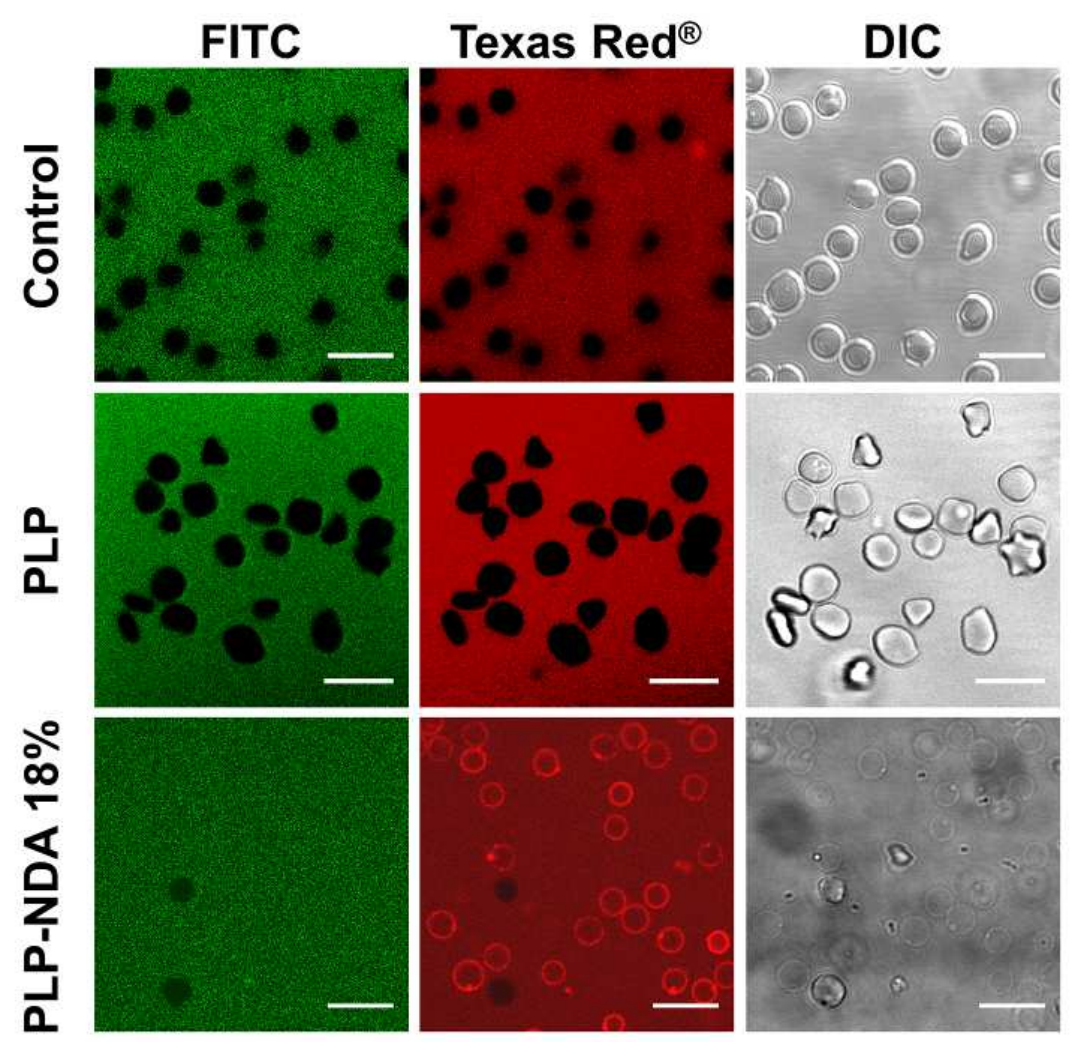

Figure 4. Confocal microscopy fluorescence and differential interference contrast (DIC) images of RBCs incubated with $10 \mu \mathrm{M}$ FITC-dextran $(\mathrm{Mw}=4 \mathrm{~K}$ Da) and $1 \mu \mathrm{M}$ Texas $\operatorname{Red} \mathbb{R}$ hydrazide in the absence or presence of the comb-like polymer PLP-NDA $18 \%$ and its linear counterpart PLP $\left(0.5 \mathrm{mg} \mathrm{mL}^{-1}\right)$ at $\mathrm{pH} 5.5$ for $30 \mathrm{~min}$. Scale bar $10 \mu \mathrm{m}$.

Figure 5 depicts the RBCs incubated with different sized FITC-dextran $\left(M_{w}=4 k-2000 k\right.$ Da) in the presence of $0.5 \mathrm{mg} \mathrm{mL}^{-1}$ PLP-NDA $18 \%$ at $\mathrm{pH} 5.5$ for $30 \mathrm{~min}$. FITC-dextran with 
the molecular weight up to $70 \mathrm{k}$ Da efficiently entered the resulted erythrocyte ghosts. The pore size formed by PLP-NDA 18\% was therefore estimated to be approximately $6 \mathrm{~nm}$ from the Stoke's radius of FITC-dextran 70k according to the supplier's information. The successful transport of FITC-dextran into RBCs at endosomal $\mathrm{pH}$ implies that the novel comb-like polymer can destabilize the endosomal membrane to efficiently release endocytosed macromolecules into the cytoplasm without totally lysing vesicular compartments. It is ideal for cytoplasmic drug delivery through endosomal-lysosomal trafficking pathways because by achieving this cytotoxicity can be minimized.

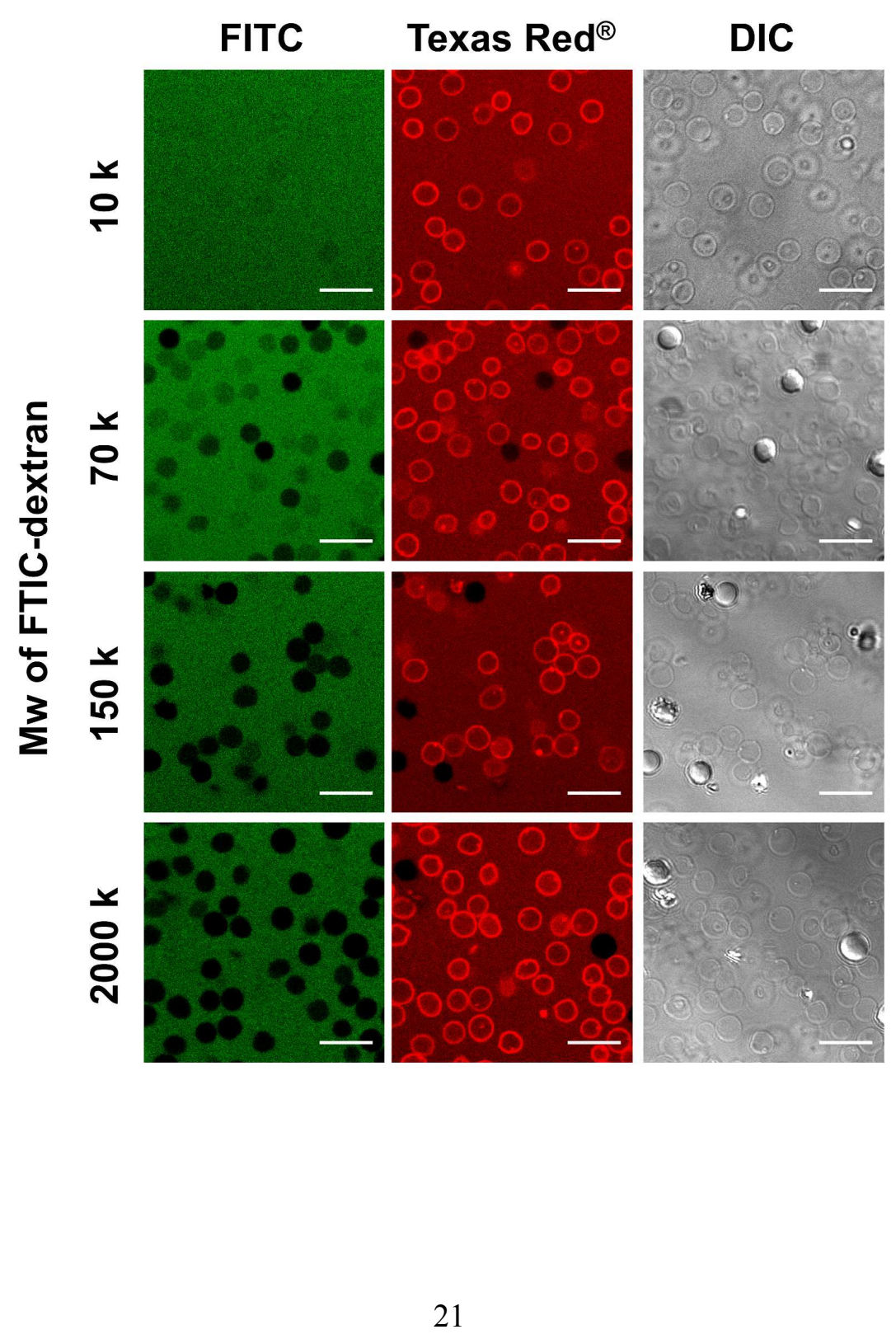


Figure 5. Confocal microscopy fluorescence and DIC images of RBCs incubated with $1 \mu \mathrm{M}$ Texas $\operatorname{Red}^{\circledR}$ hydrazide and $10 \mu \mathrm{M}$ FITC-dextran with different molecular weights in the presence of $0.5 \mathrm{mg} \mathrm{mL}^{-1}$ PLP-NDA $18 \%$ at $\mathrm{pH} 5.5$ for $30 \mathrm{~min}$. Scale bar $10 \mu \mathrm{m}$.

\subsection{In-vitro Cytotoxicity}

The concentration- and time-dependent cytotoxic effects of the comb-like polymer PLPNDA $18 \%$ toward HeLa (Figure 6A), CHO (Figure 6B) and A549 cells (Figure 6C) were assessed by Alamar Blue assay. PLP-NDA 18\% displayed no or limited cytotoxicity toward all the three cell lines within the concentration range of $0.005-0.5 \mathrm{mg} \mathrm{mL}^{-1}$ after treatment for up to $48 \mathrm{~h}$. With further increasing the polymer concentration from 1.0 to $10.0 \mathrm{mg} \mathrm{mL}^{-1}$, HeLa, CHO and A549 showed different levels of tolerance to PLP-NDA 18\%. The $\mathrm{IC}_{50}$ (i.e. the concentration leading to inhibition of $50 \%$ cell viability) of PLP-NDA $18 \%$ against HeLa after $12 \mathrm{~h}$ of treatment was $2.94 \pm 0.28 \mathrm{mg} \mathrm{mL}^{-1}$, while it decreased to $1.59 \pm 0.22$ and $1.05 \pm$ $0.14 \mathrm{mg} \mathrm{mL}^{-1}$ after extended treatment for $24 \mathrm{~h}$ and $48 \mathrm{~h}$ respectively. $\mathrm{CHO}$ and $\mathrm{A} 549$ cells demonstrated the increasingly better tolerance than HeLa cells, with an increase in $\mathrm{IC}_{50}$ to $2.81 \pm 0.95$ and $4.51 \pm 0.06 \mathrm{mg} \mathrm{mL}^{-1}$ respectively after $48 \mathrm{~h}$ of treatment. Compared with the cytotoxic effects of its linear counterpart PLP (Figure S5), the comb-like polymer PLP-NDA $18 \%$ did not exhibit significant changes in the viability of HeLa, CHO and A549 cells within the polymer concentration range $\left(0.005-1.0 \mathrm{mg} \mathrm{mL}^{-1}\right)$ after treatment for up to $48 \mathrm{~h}$. This indicates that incorporation of the hydrophobic relatively long NDA side chains onto the PLP backbone did not induce considerable cytotoxicity. When the polymer concentration was sufficiently high $\left(5.0-10.0 \mathrm{mg} \mathrm{mL} \mathrm{m}^{-1}\right)$, PLP-NDA $18 \%$ displayed a relatively higher cytotoxicity than PLP. 

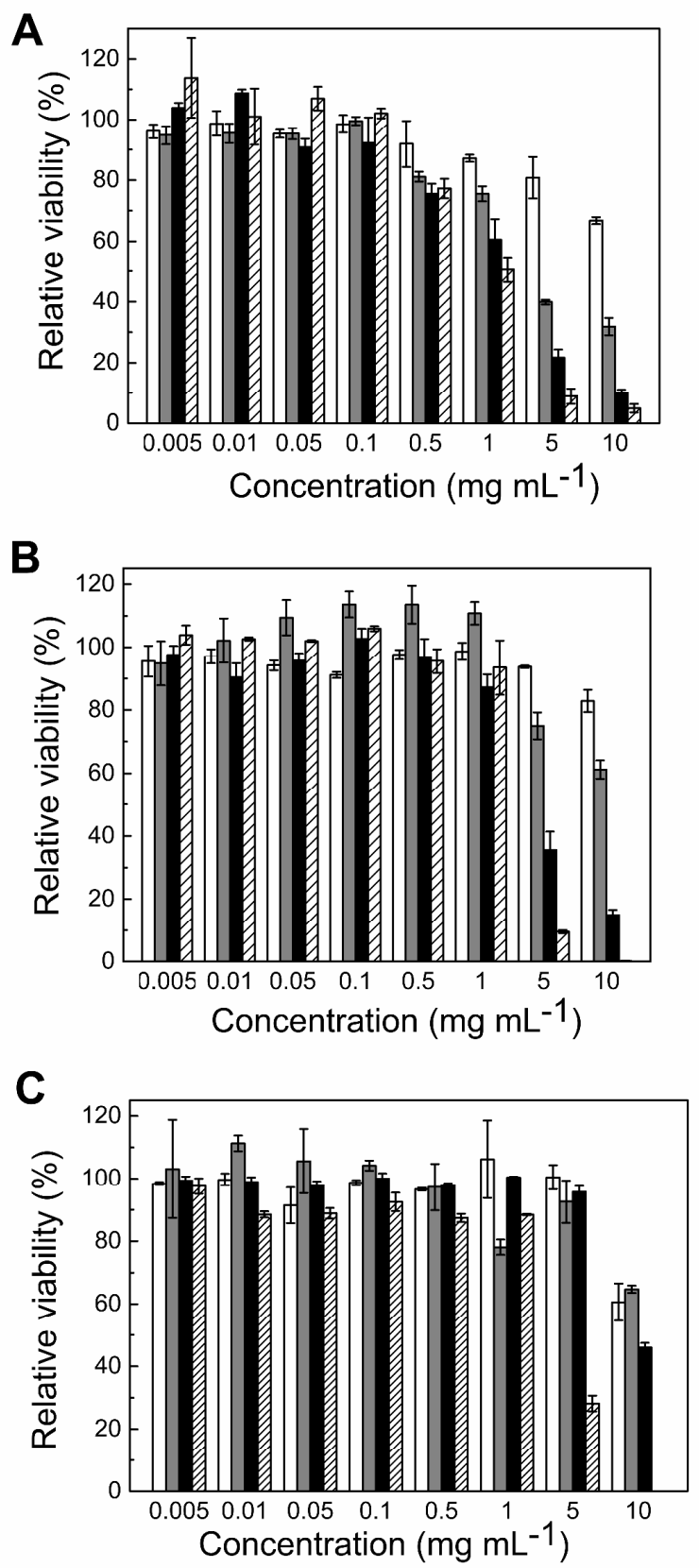

Figure 6. Relative viabilities of (A) HeLa, (B) CHO and (C) A549 cells incubated with PLPNDA $18 \%$ at various concentrations for $4 \mathrm{~h}$ (blank columns), $12 \mathrm{~h}$ (grey columns), $24 \mathrm{~h}$ (black columns) and $48 \mathrm{~h}$ (striped columns).

\subsection{Release of Endocytosed Materials from Intracellular Vesicles}

The potential of the comb-like PLP-NDA polymers to release endocytosed materials into the cytoplasm of different cell lines, such as human cervical carcinoma HeLa cells (Figure 
7A), human lung carcinoma A549 cells (Figure 7B) and non-cancerous CHO cells (Figure 7C), were assessed using membrane-impermeable calcein as a model drug. In the absence of polymer (the control), bright punctate spots were observed in all the three cell lines (Figure S6). This was due to the entrapment of the membrane impermeable fluorophore within intracellular vesicles after endocytosis ${ }^{24}$. As shown in Figure S6, cotreatment with $0.5 \mathrm{mg}$ $\mathrm{mL}^{-1} \mathrm{PLP}$ and $2.0 \mathrm{mg} \mathrm{mL}^{-1}$ calcein resulted in a similar calcein-release profile compared to the control. As comparison, in Figure 7, the presence of $0.5 \mathrm{mg} \mathrm{mL}^{-1}$ PLP-NDA $18 \%$ led to diffuse green fluorescence spreading over all the three cell lines, indicating the comb-like polymer mediated release of endocytosed calcein into the cytoplasm and the applicability of the system in various cancerous and non-cancerous cells. The ability to significantly enhance the release of endocytosed materials into the cytoplasm through $\mathrm{pH}$-mediated membrane disruption, together with its no or low cytotoxicity, suggests the promising applications of the comb-like PLP-NDA polymer in cytoplasmic delivery of therapeutic agents. 


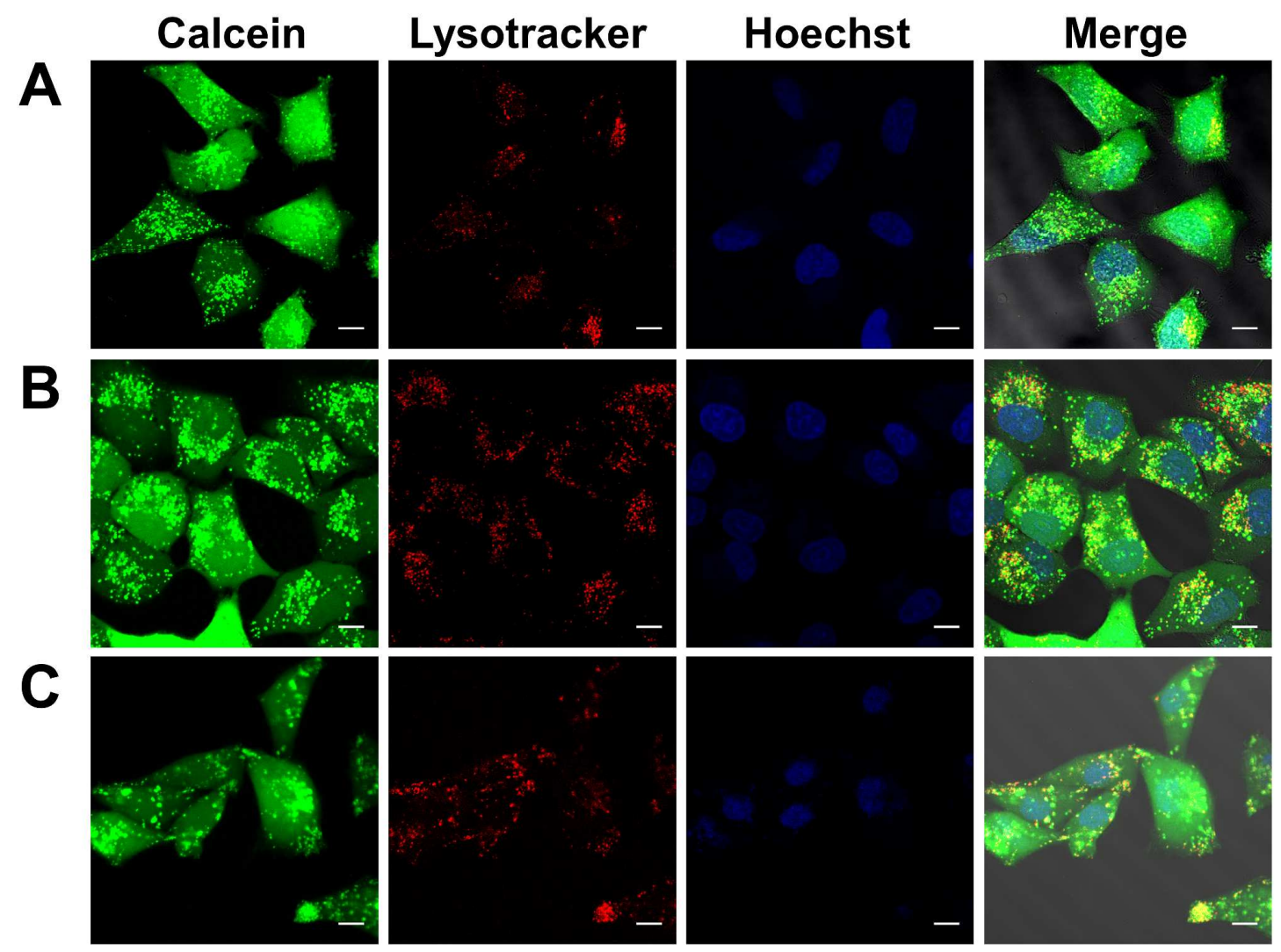

Figure 7. Confocal microscopy images of (A) Hela, (B) A549 and (C) CHO cells showing the subcellular distribution of calcein fluorescence. The cells were cotreated with $2.0 \mathrm{mg} \mathrm{mL}$ ${ }^{1}$ calcein and $0.5 \mathrm{mg} \mathrm{mL}^{-1}$ PLP-NDA $18 \%$. Images were acquired after $1 \mathrm{~h}$ of uptake and $3 \mathrm{~h}$ of further incubation in fresh DMEM for HeLa and CHO cells $(2 \mathrm{~h}$ of uptake and $2 \mathrm{~h}$ of further incubation for A549 cells). Scale bar: $10 \mu \mathrm{m}$.

\section{CONCLUSIONS}

pH-responsive, comb-like PLP-NDA polymers have been synthesized by grafting hydrophobic relatively long NDA alkyl chains onto the backbone of a linear pseudopeptide, PLP, at different degrees of substitution. The pH-responsive changes in conformation, hydrodynamic size and hemolytic activity could be manipulated by controlling the amount of NDA side-chain moieties. The significantly enhanced hydrophobicity and comb-like structure enabled the optimal polymer PLP-NDA $18 \%$ to have a vastly superior membrane-disruptive ability at endosomal $\mathrm{pH}$ compared to its linear counterpart PLP. At $0.5 \mathrm{mg} \mathrm{mL}^{-1}$, PLP-NDA 
$18 \%$ caused complete hemolysis of RBCs at $\mathrm{pH} 5.5$, while $0.5 \%$ hemolysis was achieved for its linear counterpart PLP under the same condition. The excellent membrane disruption of the comb-like polymer at endosomal $\mathrm{pH}$ was dilution-independent. The formation of ghost cells indicates the pore formation mechanism of cell membrane disruption. The comb-like polymer showed no or limited cytotoxicity at physiological $\mathrm{pH}$. Its ability to efficiently release endocytosed materials into the cytoplasm of various cancerous and non-cancerous cell lines suggests its potential for cytoplasmic drug delivery applications.

\section{ASSOCIATED CONTENT}

\section{SUPPORTING INFORMATION}

The Supporting Information is available free of charge on the ACS Publications website at http://pubs.acs.org. Additional structural characterization data including ${ }^{1} \mathrm{H}-\mathrm{NMR}$ and FT-IR spectra of PLP-NDA 18\%, pH-dependent transmittance of PLP and various PLP-NDA polymers, confocal microscopy fluorescence images of RBCs incubated FITC-dextran and Texas Red ${ }^{\circledR}$ hydrazide in the absence or presence of PLP and PLP-NDA $18 \%$ at $\mathrm{pH} 7.4$, relative viabilities of $\mathrm{HeLa}, \mathrm{CHO}$ and A549 cells treated with PLP, confocal microscopy images of HeLa, A549 and CHO cells treated with calcein only or both calcein and PLP.

\section{AUTHOR INFORMATION}

\section{Corresponding Author}

* Tel: +44 (0)20 75942070. Fax: +44 (0)20 75945638. Email: rongjun.chen@,imperial.ac.uk

\section{Author Contributions}

R.C. designed and supervised the research; S.C. performed all of the research with help from S.W., M.K. and M.B.; S.C. and R.C. analyzed data; S.C. and R.C. wrote the paper. All authors have read, commented on, and approved the final version of the paper. 


\section{Notes}

The authors declare no competing financial interest.

\section{DATA ACCESS STATEMENT}

Data underlying this article can be accessed on Zenodo (www.zenodo.org) at DOI: 10.5281/zenodo.237043, and is openly available under the Creative Commons CC-BY license.

\section{ACKNOWLEDGEMENTS}

The authors would like to thank the Department of Chemical Engineering at Imperial College London for funding this project and for providing to S.C. and M.B. fully-funded PhD Scholarships. S.W. is supported by the Marie Curie Actions under EU FP7 Initial Training Network SNAL 608184. M.K. is supported by an Industrial CASE PhD Studentship funded jointly by the Biotechnology and Biological Sciences Research Council (BBSRC, UK) and MedImmune (UK). The authors would also like to acknowledge Dr Geoff Baldwin for access to the HORIBA FluoroMax spectrofluorometer and Dr. Joaõ Cabral for access to the Malvern Zetasizer Nano S dynamic light scattering system.

\section{REFERENCES}

(1) Hoffman, A. S. Stimuli-Responsive Polymers: Biomedical Applications and Challenges for Clinical Translation. Adv. Drug Deliv. Rev. 2013, 65 (1), 10-16.

(2) Canton, I.; Battaglia, G. Endocytosis at the Nanoscale. Chem. Soc. Rev. 2012, 41 (7), 2718-2739.

(3) Han, X.; Bushweller, J. H.; Cafiso, D. S.; Tamm, L. K. Membrane Structure and 
Fusion-Triggering Conformational Change of the Fusion Domain from Influenza Hemagglutinin. Nat. Struct. Biol. 2001, 8 (8), 715-720.

(4) Skehel, J. J.; Bayley, P. M.; Brown, E. B.; Martin, S. R.; Waterfield, M. D.; White, J. M.; Wilson, I. A.; Wiley, D. C. Changes in the Conformation of Influenza Virus Hemagglutinin at the $\mathrm{pH}$ Optimum of Virus-Mediated Membrane Fusion. Proc. Natl. Acad. Sci. 1982, $79(4), 968-972$.

(5) Stuart, M. A. C.; Huck, W. T. S.; Genzer, J.; Müller, M.; Ober, C.; Stamm, M.; Sukhorukov, G. B.; Szleifer, I.; Tsukruk, V. V; Urban, M.; Winnik, F.; Zauscher, S.; Luzinov, I.; Minko, S. Emerging Applications of Stimuli-Responsive Polymer Materials. Nat. Mater. 2010, 9 (2), 101-113.

(6) Mura, S.; Nicolas, J.; Couvreur, P. Stimuli-Responsive Nanocarriers for Drug Delivery. Nat. Mater. 2013, 12 (11), 991-1003.

(7) Fleige, E.; Quadir, M. A.; Haag, R. Stimuli-Responsive Polymeric Nanocarriers for the Controlled Transport of Active Compounds: Concepts and Applications. Adv. Drug Deliv. Rev. 2012, 64 (9), 866-884.

(8) Lee, K.; Lingampalli, N.; Pisano, A. P.; Murthy, N.; So, H. Physical Delivery of Macromolecules Using High-Aspect Ratio Nanostructured Materials. ACS Appl. Mater. Interfaces 2015, 7 (42), 23387-23397.

(9) El-Sayed, M. E.; Hoffman, A. S.; Stayton, P. S. Smart Polymeric Carriers for Enhanced Intracellular Delivery of Therapeutic Macromolecules. Expert Opin. Biol. Ther. 2015, 5 (1), 23-32.

(10) Chen, S.; Chen, R. A Virus-Mimicking, Endosomolytic Liposomal System for Efficient, pH-Triggered Intracellular Drug Delivery. ACS Appl. Mater. Interfaces 2016, $8(34), 22457-22467$.

(11) Wang, H.C.; Zhang, Y.; Possanza, C. M.; Zimmerman, S. C.; Cheng, J.; Moore, J. S.; 
Harris, K.; Katz, J. S. Trigger Chemistries for Better Industrial Formulations. ACS Appl. Mater. Interfaces 2015, 7 (12), 6369-6382.

(12) Yessine, M. A.; Leroux, J. C. Membrane-Destabilizing Polyanions: Interaction with Lipid Bilayers and Endosomal Escape of Biomacromolecules. Adv. Drug Deliv. Rev. 2004, $56(7), 999-1021$.

(13) Motornov, M.; Roiter, Y.; Tokarev, I.; Minko, S. Stimuli-Responsive Nanoparticles, Nanogels and Capsules for Integrated Multifunctional Intelligent Systems. Prog. Polym. Sci. 2010, 35 (1-2), 174-211.

(14) Chen, R. Polymers in Drug Delivery: Concepts, Developments and Potential. In Drug Delivery Systems: Advanced Technologies Potentially Applicable in Personalised Treatment; Coelho, J., Ed.; Advances in Predictive, Preventive and Personalised Medicine; Springer Netherlands: Dordrecht, 2013; Vol. 4.

(15) Ho, V. H. B.; Slater, N. K. H.; Chen, R. pH-Responsive Endosomolytic PseudoPeptides for Drug Delivery to Multicellular Spheroids Tumour Models. Biomaterials 2011, 32 (11), 2953-2958.

(16) Chen, R.; Yue, Z.; Eccleston, M. E.; Williams, S.; Slater, N. K. H. Modulation of Cell Membrane Disruption by pH-Responsive Pseudo-Peptides through Grafting with Hydrophilic Side Chains. J. Control. Release 2005, 108 (1), 63-72.

(17) Murthy, N.; Robichaud, J. R.; Tirrell, D. A.; Stayton, P. S.; Hoffman, A. S. The Design and Synthesis of Polymers for Eukaryotic Membrane Disruption. J. Control. Release 1999, $61(1-2), 137-143$.

(18) Henry, S. M.; El-Sayed, M. E. H.; Pirie, C. M.; Hoffman, A. S.; Stayton, P. S. pHResponsive Poly(styrene-Alt-Maleic Anhydride) Alkylamide Copolymers for Intracellular Drug Delivery. Biomacromolecules 2006, 7 (8), 2407-2414.

(19) Chen, R.; Eccleston, M. E.; Yue, Z.; Slater, N. K. H. Synthesis and pH-Responsive 
Properties of Pseudo-Peptides Containing Hydrophobic Amino Acid Grafts. J. Mater. Chem. 2009, 19 (24), 4217-4224.

(20) Cox, D. L. N. and M. M. Lehninger Principles of Biochemistry, 5th editio.; W.H.Freeman and Company, New York, 2008.

(21) Eccleston, M. E.; Slater, N. K. H.; Tighe, B. J. Synthetic Routes to Responsive Polymers; Co-Polycondensation of Tri-Functional Amino Acids with Diacylchlorides. React. Funct. Polym. 1999, 42 (2), 147-161.

(22) Eccleston, M. E.; Kuiper, M.; Gilchrist, F. M.; Slater, N. K. H. pH-Responsive Pseudo-Peptides for Cell Membrane Disruption. J. Control. Release 2000, 69 (2), 297307.

(23) Chen, R.; Khormaee, S.; Eccleston, M. E.; Slater, N. K. H. Effect of L-Leucine Graft Content on Aqueous Solution Behavior and Membrane-Lytic Activity of a pHResponsive Pseudopeptide. Biomacromolecules 2009, 10 (9), 2601-2608.

(24) Chen, R.; Khormaee, S.; Eccleston, M. E.; Slater, N. K. H. The Role of Hydrophobic Amino Acid Grafts in the Enhancement of Membrane Disruptive Activity of $\mathrm{pH}$ Responsive Pseudo-Peptides. Biomaterials 2009, 30 (10), 1954-1961.

(25) Schmaljohann, D. Thermo- and pH-Responsive Polymers in Drug Delivery. Adv. Drug Deliv. Rev. 2006, 58 (15), 1655-1670.

(26) Kang, H. S.; Yang, S. R.; Kim, J. D.; Han, S. H.; Chang, I. S. Effects of Grafted Alkyl Groups on Aggregation Behavior of Amphiphilic Poly(aspartic Acid). Langmuir 2001, 17 (24), 7501-7506.

(27) Kang, H.; Kim, J. D.; Han, S. H.; Chang, I. S. Self-Aggregates of poly(2-Hydroxyethyl Aspartamide) Copolymers Loaded with Methotrexate by Physical and Chemical Entrapments. J. Control. Release 2002, 81 (1-2), 135-144.

(28) Chen, R.; Yue, Z.; Eccleston, M. E.; Slater, N. K. H. Aqueous Solution Behaviour and 
Membrane Disruptive Activity of pH-Responsive PEGylated Pseudo-Peptides and Their Intracellular Distribution. Biomaterials 2008, 29 (32), 4333-4340.

(29) Iversen, T. G.; Skotland, T.; Sandvig, K. Endocytosis and Intracellular Transport of Nanoparticles: Present Knowledge and Need for Future Studies. Nano Today 2011, 6 (2), 176-185.

(30) Vial, F.; Rabhi, S.; Tribet, C. Association of Octyl-Modified Poly(acrylic Acid) onto Unilamellar Vesicles of Lipids and Kinetics of Vesicle Disruption. Langmuir 2005, 21 (3), 853-862.

(31) Thomas, J. L.; Borden, K. A.; Tirrell, D. A. Modulation of Mobilities of Fluorescent Membrane Probes by Adsorption of a Hydrophobic Polyelectrolyte. Macromolecules 1996, $29(7), 2570-2576$.

(32) Polozova, A.; Winnik, F. M. Mechanism of the Interaction of HydrophobicallyModified Poly-(N-Isopropylacrylamides) with Liposomes. Biochim. Biophys. Acta Biomembr. 1997, 1326 (2), 213-224.

(33) Marie, E.; Sagan, S.; Cribier, S.; Tribet, C. Amphiphilic Macromolecules on Cell Membranes: From Protective Layers to Controlled Permeabilization. J. Membr. Biol. 2014, 247 (9-10), 861-881.

(34) Tribet, C.; Vial, F. Flexible Macromolecules Attached to Lipid Bilayers: Impact on Fluidity, Curvature, Permeability and Stability of the Membranes. Soft Matter 2008, 4 (1), 68 .

(35) Pack, D. W.; Hoffman, A. S.; Pun, S.; Stayton, P. S. Design and Development of Polymers for Gene Delivery. Nat. Rev. Drug Discov. 2005, 4 (7), 581-593.

(36) Linhardt, J. G.; Tirrell, D. A. pH-Induced Fusion and Lysis of Phosphatidylcholine Vesicles by the Hydrophobic Polyelectrolyte Poly (2-Ethylacrylic Acid). Langmuir 2000, $16(1), 122-127$. 
(37) Matsuzaki, K.; Yoneyama, S.; Miyajima, K. Pore Formation and Translocation of Melittin. Biophys. J. 1997, 73 (2), 831-838.

(38) Matteo, R.; Proverbio, T.; Córdova, K.; Proverbio, F.; Marín, R. Preeclampsia, Lipid Peroxidation, and Calcium Adenosine Triphosphatase Activity of Red Blood Cell Ghosts. Am. J. Obstet. Gynecol. 1998, 178 (2), 402-408.

(39) Chung, J. C.; Gross, D. J.; Thomas, J. L.; Tirrell, D. A.; Opsahl-Ong, L. R. pHSensitive, Cation-Selective Channels Formed by a Simple Synthetic Polyelectrolyte in Artificial Bilayer Membranes. Macromolecules 1996, 29 (13), 4636-4641.

(40) Resh, M. D. Covalent Lipid Modifications of Proteins. Curr. Biol. 2013, 23 (10), R431-R435. 


\section{TABLE OF CONTENTS GRAPHIC}

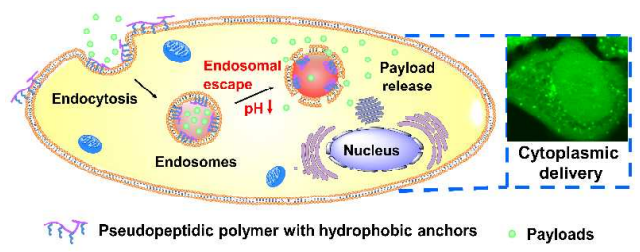

14

15

16

17

18

19

20

21

22

23

24

25

26

27

28

29

30

31

32

33

34

35

36

37

38

39

40

41

42

43

44

45

46

47

48

49

50

51

52

53

54

55

56

57

58

59

60 